\title{
RECURSOS HUMANOS: CUSTO OU INVESTIMENTO?
}

Hugo Coimbra*

Os recursos humanos constituem indubitavelmente o centro fulcral das organizações. Esta ideia é deveras reforçada no caso das P.M.E.(s). Sem dúvida o bom funcionamento duma empresa depende em última instância da forma como as pessoas são capazes de responder, no sentido da prossecução dos objectivos fixados.

As P.M.E.(s) constituem inequivocamente o grosso da coluna do nosso tecido empresarial e esta afirmação tem especial cabimento se focalizarmos a análise numa perspectiva regional.

A tipologia mais característica deste segmento está ligada a vectores principais que globalmente são similares e dos quais passamos a citar:

1) - Estrutura familiar ou pessoal

2) - Centralismo de Gestão

3) - Profissionais com formação deficiente

4) — Polivalência de funções

Naturalmente que mais algumas características seriam passíveis de ser acrescentadas mas estarão sempre dependentes da área de actuação da empresa. Os parâmetros atrás citados conduzem-nos a uma reflexão futura, visionando as consequências inerentes ao impacto provocado pela adesão plena ao mercado comunitário.

O contacto estabelecido, de forma permanente, com os empresários leva-nos a constatar um conjunto de apreensões quanto à capacidade de resposta a este tão grande desafio. Estes níveis de apreensão situam-se maioritariamente na área tecnológica, mas também com particular acuidade no domínio dos recursos humanos.

* Supervisor de Estágio do Instituto Universitário de Desenvolvimento e Promoção Social — Pólo de Viseu da Universidade Católica Portuguesa. 


\section{E PORQUÊ TODO ESTE QUADRO?}

Esta reflexão é a consequência natural do constatar de todo um conjunto de problemas cujas causas se situam basicamente nas carências que apresentam esses mesmos recursos humanos. Esta ideia é extensiva a domínios que vão desde a indústria, ao comércio e aos serviços.

No entanto, gostaríamos de introduzir um novo conceito de empresa, que hoje começa, cada vez mais, a ser uma realidade concreta também entre nós, que faz a simbiose das situações anteriormente descritas - parcial ou totalmente - e que Hervé Serieux designa como empresas do $3 .^{\circ}$ tipo.

Este é também um novo desafio que se coloca aos recursos humanos. Continuando a linha de raciocínio anterior, gostaríamos ainda de frisar quais são, segundo a nossa óptica, os principais problemas que se deparam a nível dos recursos humanos nas P.M.E.(s):

1) - Falta de formação, do que resultam:

- Baixa qualidade

- Baixa produtividade

2) - Grande carência de Quadros Médios

3) - Resistência à mudança

4) — Sazonalidade da mão-de-obra (regional)

Outras situações teriam aqui cabimento mas, depois de analisar profundamente algumas empresas, foram estes itens atrás citados os que mais vezes foram pronunciados pelos empresários e que estão também em concordância com uma óptica pessoal. Retornando a cada um deles verifica-se, no que concerne ao primeiro, que felizmente já se encontram em curso acções no sentido de ultrapassar este obstáculo; é aqui devida uma palavra de apreço para o trabalho desenvolvido neste campo pelo I.E.F.P.

Apesar deste esforço, os empresários continuam a não utilizar na plenitude todos os fundos postos à sua disposição pela Comunidade Europeia, conducentes a colmatar toda esta problemática.

\section{E QUAIS AS RAZÕES QUE LEVAM A ESTA ATITUDE?}

Por um lado, o sentido negativo que foi dado à utilização desses fundos, o qual gerou um clima de desconfiança junto de algumas camadas do sector empresarial. Por outro lado, uma informação deficiente ou, melhor dizendo, feita em parâmetros que se coadunavam pouco com a maioria da nossa realidade.

No segundo item está focado um problema que nos parece extremamente 160 importante. 


\section{A CARÊNCIA DE QUADROS MÉDIOS.}

Anteriormente esta carência era suprida pelos profissionais saídos das escolas comerciais e industriais. São eles que constituem ainda hoje o sustentáculo básico do nosso país nos mais diversos sectores e dos quais, e só a título meramente exemplificativo, passaríamos a citar: a administração pública, banca, indústria pesada, etc.

Após o 25 de Abril de 1974, o ensino em Portugal foi profundamente reestruturado e a sua unificação e pretensa democratização levou ao desaparecimento deste tipo de estabelecimentos de ensino.

Para tentar obviar a este problema foi criado o ensino profissional que abrange diversas áreas, cujas instituições, as escolas profissionais, tendo um carácter eminentemente regional, começam já a dar os seus primeiros frutos.

Lembrar ainda que o processo de adesão comunitária vai criar um segmento de mercado bastante grande e para cuja resposta irão preferencialmente ser chamados Quadros Médios.

No terceiro item focaliza-se o problema da resistência à mudança e aqui também é importante saber onde se inserem as causas. Elas são naturalmente de vária ordem, mas as mais comuns estão ligadas a conceitos já perfeitamente ultrapassados e ao receio da incapacidade do acompanhamento de novas tecnologias, ou mesmo de novas formas de gestão.

\section{COMO ACTUAR ENTÃO PERANTE ESTE CONJUNTO DE SITUAÇÕES?}

O gestor, nomeadamente na área específica dos recursos humanos, deverá incrementar a transformação do tecido humano da empresa, através duma renovação significativa. Esta deverá começar a ser operada a nível das mentalidades de todos os interventores na empresa e tendo em conta que esta operação deverá iniciar-se no sentido da pirâmide invertida, ao nível do organigrama. Convém aqui salientar que muitos dos traumas e desconfiança, tão arreigados no trabalhador português, e a falta de motivação de muitos deles, para atingirem os objectivos da empresa, decorrem da deficiente formação de certos empresários, quer por não terem ainda compreendido os verdadeiros objectivos da empresa moderna, quer porque não foram capazes de os transmitir.

Ora é naquela transformação que os profissionais de recursos humanos deverão passar a desempenhar um papel de relevo, cabendo-lhes desenvolver a função pessoal em consonância com a evolução das envolventes de natureza social, política, tecnológica e financeira. Estas noções, aparentamente ligadas só à empresa de maior dimensão, têm no entanto particular assento a nível das P.M.E.(s), dado que aqui cada recurso humano deverá ser rendibilizado na plenitude das suas aptidões. 
Quanto ao problema da sazonalidade, ele é bastante sentido entre o nosso empresariado. Ultrapassar esta situação só será possível pela criação de novos e inovadores postos de trabalho que permitam a sua fixação futura.

Realmente, a função pessoal terá de ser prosseguida e direccionada pelas seguintes condicionantes:

1) Necessidade de ajustamentos ligados ao impacto causado pela introdução de novas tecnologias e pelo fluxo cada vez maior da informação, o que levará a uma redefinição, quase permanente, de funções.

2) O conceito da gestão centralizada terá que ser necessariamente substituído pelo da gestão delegada, com equipas flexíveis e polivalentes.

3) O aumento substancial da profissionalização da força de trabalho, com predomínio da massa cinzenta sobre a força muscular.

É importante modificar a ideia do trabalhador ligado à máquina. Deve, sim, verificar-se o inverso, isto é, a maior rentabilização da máquina com participação directa do operário.

4) Nova imagem do empregado modelo.

A substituição daquele que cumpre integralmente para aquele que assume responsabilidades, toma iniciativas e usa os seus superiores como consultores.

5) Rápida modificação do comportamento do candidato ao emprego.

Volta a ter bastante importância a consultoria que virá ser exercida por profissionais, já fora do exercício diário da profissão.

Uma outra noção que cada vez mais constituirá forma de obtenção de valor acrescentado, a nível de P.M.E.(s), está ligada à noção de qualidade. Nos anos noventa, por detrás de cada produto ou serviço, existirá uma sociedade onde a noção de qualidade será extraordinariamente valorizada. Os recursos humanos terão que ser dinamizados e formados no sentido da estrita observação deste parâmetro.

Um outro vector de actuação estará ligado à crescente internacionalização que vai ser operada nas empresas e mesmo a nível das P.M.E.(s). Esta internacionalização impõe uma adaptação dos quadros médios superiores.

É neste contexto que o gestor de recursos humanos vai ter que actuar, tendo em conta o processo dinâmico de mudança que, sem dúvida, é uma das características mais actuais das nossas empresas.

Os gestores de recursos humanos, no âmbito das P.M.E.(s), poderão ter um contributo decisivo para:

1) A definição duma estrutura da empresa onde a flexibilidade e a diminuição de níveis hierárquicos serão pontos-chave.

2) A definição de uma política de recursos humanos, tendo em consideração o seu dimensionamento e quantificação ideal.

3) A criação de um ambiente agradável, que permita os melhores desempenhos a nível da inovação e gestão e, bem assim, que contribuam para a realização profissional. 
4) O estabelecimento de um diálogo construtivo com organizações sindicais.

5) Procurar soluções para o inevitável incremento do "turn over" dos trabalhadores, em especial dos mais qualificados.

Nas P.M.E.(s), isto virá a ser um dado adquirido devido à adesão comunitária, pelo que a sua falta é sempre motivo negativo para as P.M.E.(s).

6) Serem veículos promotores da melhoria de produtividade, através do fornecimento de informação vital aos trabalhadores, sob diversos ângulos.

As tarefas mais clássicas da gestão de pessoal irão sofrer alterações significativas, face às mutações a que as empresas irão estar sujeitas, nos próximos anos. Estas mutações estarão directamente ligadas à introdução de novas tecnologias e ao cada vez maior domínio da informatização.

Novas situações irão aparecer neste contexto, como:

1) - PLANEAMENTO: virá a ser um instrumento importante nas P.M.E.(s), utilizando algumas tecnologias de informação.

2) - ORGANIZAÇÃO: deverá ter em conta que, devido a todo o conjunto de alterações anteriomente introduzidas, o tecido humano da empresa irá sofrer alterações qualitativas, por força do recutamento de elementos mais qualificados.

3) - MOTIVAÇÃO: terá que ter um carácter globalizante.

4) - RECRUTAMENTO E SELECÇÃO: irão ter um carácter mais elaborado.

5) - INFORMAÇÃO: crescerá em flecha e o papel dos gestores de recursos humanos será importante e difícil, pois quanto maior for a informação mais competente terão que ser.

Deixamos para análise final a formação, a qual desempenha um papel fulcral em nossos dias, no sector das P.M.E.(s). A formação passará a ser um processo dinâmico e contínuo a todos os níveis hierárquicos. Naturalmente que isto só poderá ser conseguido através de uma nova atitude mental.

Depois da análise de alguns problemas principais a nível dos recursos humanos nas P.M.E.(s), não tendo a pretensão de termos esgotado o assunto, não queríamos deixar de nos dirigir mais uma vez aos futuros Gestores de recursos humanos, cuja inserção nas P.M.E.(s) será uma realidade.

Comungo convosco uma série de apreensões que constituem um dos vossos problemas pessoais mais importantes. No vosso cérebro bailam inúmeras questões que se prendem naturalmente com a tipologia do vosso trabalho, junto das P.M.E.(s).

Uma das vossas tarefas principais passará por serem capazes de criar junto da empresa a necessidade da existência duma nova área, concretamente as de recursos humanos. 
É também de capital importância a vossa auto-motivação e a vossa disponibilidade total para a ajuda nos mais diversos sectores.

Penso também que o vosso êxito estará extraordinariamente dependente duma polivalência de funções que se vos irão deparar e que terão que desempenhar no seu devido contexto. Volto a frisar que a polivalência é um dos factores que mais pesará no vosso êxito.

Mas o vosso papel numa P.M.E., no domínio específico dos recursos humanos, é deveras motivador. Dada a precaridade dos mesmos, o Gestor de recursos humanos terá um trabalho de capital importância a vários níveis, dos quais me permito mencionar alguns:

1) - No recrutamento e selecção do pessoal.

2) - Na avaliação do desempenho (área controversa mas que começa a ser cada vez mais aplicada).

3) - $\mathrm{Na}$ reestruturação das carreiras

4) - Como agentes fomentadores de motivação, junto do pessoal.

5) - Assumirem-se como veículos de inovação.

Claro que dada a especificidade de cada empresa, as ideias anteriomente mencionadas poderão ser modificadas mas, como dizia Peter Drucker, «A mudança é a maior certeza do empresário dos anos noventa».

Para terminar queria citar-vos as palavras do líder do grupo SONAE, Eng. ${ }^{\circ}$ Belmiro de Azevedo, quando dizia que:

"Os recursos humanos eram o bem mais precioso que possuía nas suas empresas".

E eu permitir-me-ia acrescentar que, nas P.M.E.(s), eles têm estatuto de tesouro de valor incalculável, pois, apesar de todas as evoluções, será sempre o homem o "único e exclusivo recurso que gera todos os outros".

\section{BIBLIOGRAFIA}

Actas $2 .^{\circ}$ Congresso de $A P G, 1990$

ANÍBAL, A. Anselmo, COSTA, Vítor, A gestão dos recursos humanos e os direitos dos trabalhadores, Lisboa, Col. "Universitária", 38, Ed. Caminho.

Dirigir (Revista).

DRUCKER, Peter F., 1985, Factor humano e desempenho, Biblioteca Pioneira de Administração e Negócio.

CHIAVENATO, Idalberto, 1985, Recursos humanos, Editora Atlas. 